\title{
Residents wait for return to Japanese volcano island
}

\section{David Cyranoski, Tokyo}

Six months after its main eruption, Mount Oyama on the island of Miyake, 200 kilometres south of Tokyo, is still belching thousands of tonnes of toxic gas into the atmosphere every day. And Japanese volcanologists say they do not know when it is likely to stop.

This month, a meeting of the Coordinating Committee for the Prediction of Volcanic Eruptions admitted that there is no end in sight for the sulphur dioxide $\left(\mathrm{SO}_{2}\right)$ emissions.

The extraordinary volume of $\mathrm{SO}_{2}$ being given off makes it advisable to keep the residents off the island, the scientists say. Miyake's 3,900 residents have been evacuated to the mainland where health risks from the gas emissions are said to be slight.

Oyama drew attention late last June when researchers detected a movement of rising magma, which resulted in a violent underwater eruption to the west of the island. In August, a series of small earthquakes and eruptions led to the main blast on 18 August, which shot volcanic smoke several kilometres into the air and created a mammoth 1.5kilometre crater at the volcano's mouth.

There have been no strong tremors since August, leading scientists to conclude that there is little reason to expect further explosive eruptions. But they point out that the temperature at the volcano's mouth peaked in December and remains high, indicating that there is still a risk of small eruptions.

But $\mathrm{SO}_{2}$ continues to pour into the sky at a rate of tens of thousands of tonnes per day.
"This long-term expulsion of gas has never really been observed before," says Yoshiaki Ida, professor of geophysics at the University of Tokyo and chair of the coordinating committee.

The emissions are not the only surprise at Miyake. Because Oyama is a 'basaltic' volcano, it should generate a steady emission of fluid magma rock, rather than producing the violent eruptions that have characterized this incident. The fact that an eruption on the edge of the mountain, away from the volcanic peak, preceded the main eruption is also abnormal. "Unusual explosions must have been triggered by the preceding flank eruption and the collapse of the summit area, but the precise mechanism is unknown," Ida says.

Japanese volcanologists will continue to study these anomalies, and try to figure out the reasons for them. "It could be that this long-term expulsion of gas is related to the large mouth size of the crater," says Ida.

In the meantime, the island's displaced inhabitants await permission from the Tokyo metropolitan Disaster Prevention Planning Section - which takes advice from Ida's committee - to return home.

The committee will next meet in May but residents could be waiting much longer than that. "A preliminary estimate of [volume of magma in the volcano] shows that the volcano has capacity to supply sulphur dioxide for several years, but the emission may end earlier than that," says Ida.

http://hakone.eri.u-tokyo.ac.jp/vrc/erup/miyake.html http://www.aist.go.jp/GSJ/ kaz/miyakegas/COSPEC.html

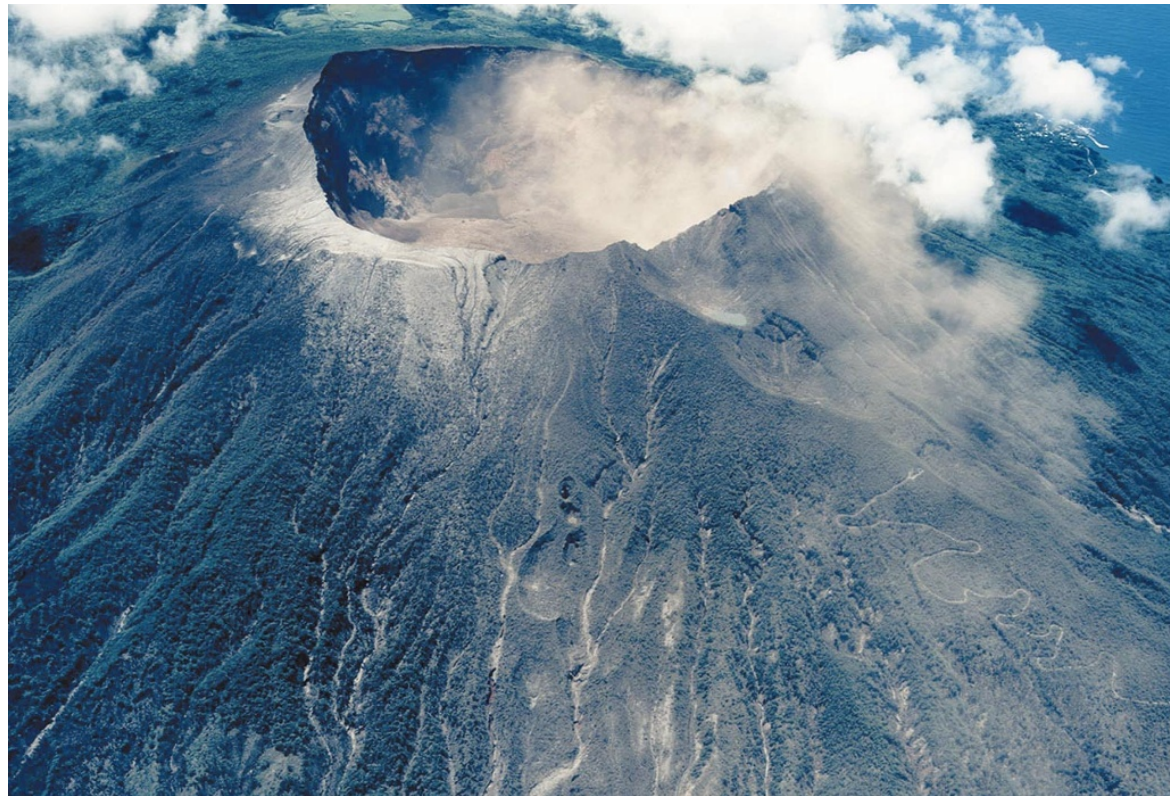

Blowing its top: Mount Oyama spews out thousands of tonnes of toxic gas every day.

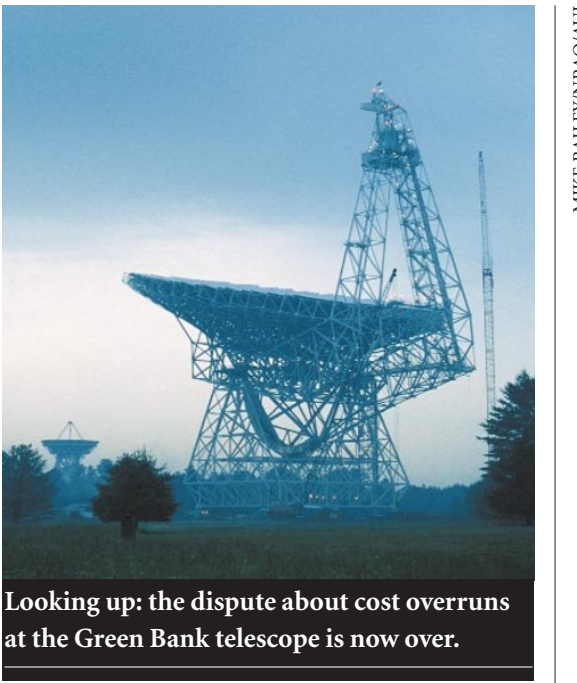

\section{Small payout over Green Bank telescope cheers astronomers}

Irwin Goodwin, Washington

An arbitrator has ruled that the government should pay only $\$ 4$ million towards cost overruns encountered by the contractor that built a huge radiotelescope at Green Bank, West Virginia.

The decision - in the face of claims from the contractor for $\$ 29$ million on top of its $\$ 55$ million contract to build the world's largest fully steerable, single-dish telescope - was good news for US astronomers, who feared the settlement would eat into the astronomy budget at the National Science Foundation (NSF).

The contractor, Radiation Systems Incorporated - later part of the Comsat Corporation - began work in 1990, with completion planned for 1994. But the telescope achieved first light on 22 August 2000 and was accepted by the National Radio Astronomy Observatory (NRAO), on behalf of the NSF, on 13 October.

In 1998, Comsat sought a further \$29 million, arguing that NRAO and its managing contractor, Associated Universities Incorporated (AUI), had forced it to perform extra work.

"This matter is finally resolved, and we can now focus our efforts on making Green Bank a world-class telescope," says Paul Vanden Bout, NRAO's director.

Three days after it achieved first light, the GBT was opened by its original sponsor, senator Robert Byrd (Democrat, West Virginia), whose name it now carries.

But even as AUI and NSF officials worried about the possibility of an expensive settlement, Byrd discreetly slipped \$15 million into the NSF's budget bill for this year to cover astronomy facility costs, including \$8 million specifically for the GBT. 